\title{
Reversible structural transformations in a Co(II)-based 2D dynamic metal-organic framework showing selective solvent uptake
}

\author{
SANJOG S NAGARKAR and SUJIT K GHOSH* \\ Indian Institute of Science Education and Research (IISER), Dr. Homi Bhabha Road, Pune, \\ Maharashtra 411 008, India \\ e-mail:sghosh@iiserpune.ac.in
}

MS received 17 October 2013; accepted 21 July 2014

\begin{abstract}
A Co(II)-based two-dimensional (2D) metal-organic framework (MOF) $\left[\mathrm{Co}(\mathrm{pca})(\mathrm{bdc})_{0.5}\left(\mathrm{H}_{2} \mathrm{O}\right)_{2}\right]$ (1) $\{$ pca $=$ pyrazine carboxylic acid, and bdc $=1$,4-benzene dicarboxylic acid $\}$ was synthesized solvothermally. The compound loses the coordinated lattice water molecules on heating which is accompanied by solidstate structural transformation to yield dehydrated phase $\left[\mathrm{Co}(\mathrm{pca})(\mathrm{bdc})_{0.5}\right]\left(\mathbf{1}^{\prime}\right)$. The hydrated structure can be regained by exposing $\mathbf{1}^{\prime}$ to water vapour $\left(\mathbf{1}^{\prime \prime}\right)$. These reversible solid-state structural transformations are accompanied by a visible colour change in the material. The dehydrated compound also shows highly selective water uptake over other solvents like $\mathrm{MeOH}$, EtOH, THF. This selective water uptake can be ascribed to the high affinity of polar water molecule towards the open metal site created on heating. The present report provides important insights into the reversible structural transformations observed due to variable coordination number of the central metal ion and transformability of the framework. The selective water uptake over alcohols along with visible colour change demonstrates the potential of the present compound in bio-alcohol purification.
\end{abstract}

Keywords. Metal-organic frameworks; coordination polymers; selective uptake; dynamic framework.

\section{Introduction}

The limited natural resources like gas and oil have accelerated the research in the field of alternate sustainable energy resources. ${ }^{1-3}$ Bio-alcohols are getting increased attention as sustainable energy resource which are expected to be commercialized in the near future. Despite its high potential, water as an unavoidable impurity present in the bio-alcohols restricts its extensive use. ${ }^{4-6}$ The conventional distillation approach for separation of water from alcohols is energy intensive and ineffective. ${ }^{7-9}$ Adsorption-based separation methods are more promising in this respect as they are energy efficient processes. ${ }^{10}$ Thus, the effective and efficient separation of water from water-alcohol mixture by adsorption methods is highly anticipated.

The metal-organic frameworks (MOFs) and coordination polymers (CP) are well known for their designable architecture and porous properties, which along with the ease of material fabrication, feasibility of hybridization with other materials make MOFs significant materials. ${ }^{11-13}$ Since their discovery, these materials have been extensively studied for storage, separation, magnetism, sensing, biomedical and very recently for ion conduction applications. ${ }^{14-21}$ Hydrogen

*For correspondence bonding and van der Waals interactions have been explored especially to get selective separation through host guest interaction like $\pi-\pi .^{22-24}$ In this regard, the soft, porous crystals or dynamic frameworks have attracted much attention owing to the framework flexibility in addition to designable nature of the framework. ${ }^{25-27}$ The flexibility provides an additional tool to control the guest uptake and gives rise to unusual phenomena like gate opening and selective adsorption. ${ }^{24-29}$ These solid state transformations are triggered by external stimuli like heat, light, pressure, etc., and these are more attractive compared to rigid frameworks. ${ }^{30-32}$ Despite these promising properties, reports of dynamic MOFs are limited due to the difficulties in the characterization of such solid-state structural transformations. Thus, the design and synthesis of dynamic MOF with high affinity for water becomes handy in separation applications. Also, for a material to be smart sorbent, in addition to selective and efficient sorption it should also show some change in properties like colour, magnetism, etc., so that it can be a self-indicator to identify the extent of saturation of sorbent.

Herein, we report a $\mathrm{Co}(\mathrm{II})$-based dynamic metalorganic framework $\left[\mathrm{Co}(\mathrm{pca})(\mathrm{bdc})_{0.5}\left(\mathrm{H}_{2} \mathrm{O}\right)_{2}\right](\mathbf{1})$ synthesized solvothermally. The compound exhibits reversible solid-state structural transformations as confirmed by 
PXRD and TGA analysis, accompanied by distinct colour change. The solvent sorption isotherms of the activated compound shows highly selective uptake of $\mathrm{H}_{2} \mathrm{O}$ over other solvents like $\mathrm{MeOH}$, EtOH, THF, toluene, etc. This highly selective $\mathrm{H}_{2} \mathrm{O}$ uptake can be ascribed to the open metal sites generated on dehydration and the highly polar nature of water. The highly selective $\mathrm{H}_{2} \mathrm{O}$ uptake over $\mathrm{EtOH}$ and the colour change associated with it shows potential of the present compound to separate water from alcohol-water mixture.

\section{Experimental}

\subsection{Materials}

All the reagents were commercially available and used as supplied without further purification. Pyrazine carboxylic acid and 1,4-benzene dicarboxylic acid were purchased from Aldrich Chemical Co. Cobalt(II) nitrate and $\mathrm{NaOH}$ were purchased from Merck India. All other solvents used were purchased locally.

\subsection{Synthesis of $\left[\mathrm{Co}(\mathrm{pca})(\mathrm{bdc})_{0.5}\left(\mathrm{H}_{2} \mathrm{O}\right)_{2}\right](\mathbf{1})$}

The reaction between $\mathrm{Co}\left(\mathrm{NO}_{3}\right)_{2} \cdot 4 \mathrm{H}_{2} \mathrm{O}(1 \mathrm{mmol})$, pyrazine carboxylic acid (pcaH, $1 \mathrm{mmol}$ ), 1,4-benzene dicarboxylic acid $\left(\mathrm{bdcH}_{2}, 1 \mathrm{mmol}\right)$ and $\mathrm{NaOH}$ ( $1 \mathrm{mmol}$ ), in $6 \mathrm{~mL}$ of $\mathrm{H}_{2} \mathrm{O}$ at $160^{\circ} \mathrm{C}$ for 3 days in a Teflon-lined vessel gave wine red single crystals of $\mathbf{1}$ in $\sim 60 \%$ yield.

\subsection{Dehydration $\left[\mathrm{Co}(p c a)(b d c)_{0.5}\right]\left(\mathbf{I}^{\prime}\right)$}

The wine red single crystals of $\mathbf{1}$ were grinded to get fine powder which then was heated at $140^{\circ} \mathrm{C}$ for $8 \mathrm{~h}$ under reduced pressure. The dehydrated phase was obtained as brown powder.

\subsection{Rehydration $\left[\mathrm{Co}(\mathrm{pca})(\mathrm{bdc})_{0.5}\left(\mathrm{H}_{2} \mathrm{O}\right)_{2}\right]\left(\mathbf{I}^{\prime \prime}\right)$}

The glass vial containing dehydrated sample was kept in a slightly bigger screw cap bottle containing water. After exposing to water vapour for 3 days at room temperature, the rehydrated phase was obtained. Rehydration can also be achieved by exposing the dehydrated sample to air, but complete rehydration takes a long time ( $\sim 30$ days).

\section{$2.5 X$ X-Ray crystallography}

Single-crystal X-ray data on $\mathbf{1}$ were collected at $200 \mathrm{~K}$ on a Bruker KAPPA APEX II CCD Duo diffractometer (operated at $1500 \mathrm{~W}$ power: $50 \mathrm{kV}, 30 \mathrm{~mA}$ ) using graphite-monochromated Mo $\mathrm{K} \alpha$ radiation $(\lambda=0.710$ $73 \AA$ A). The crystal was on nylon CryoLoops (Hampton Research) with Paraton-N (Hampton Research). The data integration and reduction were processed with SAINT $^{33}$ software. A multi-scan absorption correction was applied to the collected reflections. The structure was solved by the direct method using SHELXTL ${ }^{34}$ and was refined on $\mathrm{F}^{2}$ by full matrix least-squares technique using the SHELXL-97 $7^{35}$ program package within the WINGX ${ }^{36}$ program. All non-hydrogen atoms were refined anisotropically. All hydrogen atoms were located in successive difference Fourier maps, and they were treated as riding atoms using SHELXL default parameters. The structures were examined using the Adsym subroutine of PLATON ${ }^{37}$ to ensure that no additional symmetry could be applied to the models (table 1).

\subsection{Physical measurements}

FT-IR spectra were measured on a Nicolet 6700 FTIR spectrophotometer by making $\mathrm{KBr}$ pellets (400$4000 \mathrm{~cm}^{-1}$ ), X-ray powder patterns were recorded on a Bruker D8 advanced X-ray diffractometer using $\mathrm{Cu}$

Table 1. Crystal data and structure refinement for compound 1.

\begin{tabular}{|c|c|}
\hline Compound & 1 \\
\hline Empirical formula & C9 H9 Co N2 O6 \\
\hline Formula weight & 297.09 \\
\hline Temperature (K) & $200(2)$ \\
\hline Wavelength $(\AA)$ & 0.71073 \\
\hline Crystal system & Orthorhombic \\
\hline Space group & $P b c a$ \\
\hline$a(\AA)$ & $11.8920(15)$ \\
\hline$b(\AA)$ & $11.1027(14)$ \\
\hline$c(\AA)$ & $15.673(2)$ \\
\hline Volume $(\AA)$ & $2069.4(5)$ \\
\hline $\mathrm{Z}$ & 8 \\
\hline Calculated density $\left(\mathrm{mg} \mathrm{m}^{-3}\right)$ & 1.906 \\
\hline Absorption coefficient $\left(\mathrm{mm}^{-1}\right)$ & 1.941 \\
\hline $\mathrm{F}(000)$ & 1224 \\
\hline Theta range $\left(^{\circ}\right)$ & $2.85-29.31$ \\
\hline Reflections collected/unique & $11385 / 2746$ \\
\hline Completeness to $\theta / \%$ & 99.10 \\
\hline Max./Min. transmission & $0.8296 / 0.6975$ \\
\hline Data/restraints parameters & $2746 / 0 / 175$ \\
\hline Goodness-of-fit on $\mathrm{F}^{2}$ & 1.058 \\
\hline Final $\mathrm{R}$ indices $\mathrm{I}>2 \sigma(\mathrm{I}){ }^{(\mathrm{a})}$ & 0.0213 \\
\hline $\mathrm{R}$ indices (all data) & 0.0570 \\
\hline
\end{tabular}

${ }^{\mathrm{a}} \mathrm{R}_{1}=\Sigma|| \mathrm{F}_{0}|-| \mathrm{F}_{\mathrm{c}}|| / \Sigma\left|\mathrm{F}_{0}\right|$,

${ }^{\mathrm{b}_{\mathrm{wR}}}=\left[\Sigma\left(w\left(\mathrm{~F}_{0}^{2}-\mathrm{F}_{\mathrm{c}}\right)^{2}\right) / \Sigma \mathrm{w}\left(\mathrm{F}_{0}^{2}\right)^{2}\right]^{1 / 2}$. 
$\mathrm{K} \alpha$ radiation $(\lambda=1.5406 \AA)$ with scan rate $0.4 \mathrm{~s} / \mathrm{step}$ and step size $0.01^{\circ}$, and thermogravimetric analyses were recorded with heating rate of $10^{\circ} \mathrm{C} / \mathrm{min}$ under $\mathrm{N}_{2}$ atmosphere on a Perkin-Elmer STA 6000 TGA analyzer.

\subsection{Low pressure sorption measurement}

Low pressure gas and solvent sorption measurements were measured using BelSorp-max (Bel Japan). The sample 1 was heated at $140^{\circ} \mathrm{C}$ for $2 \mathrm{~h}$ in oil bath prior to adsorption measurement to activate the sample. The activated sample was further heated at $120^{\circ} \mathrm{C}$ under vacuum for $5 \mathrm{~h}$ using BelPrepvacII and purged with $\mathrm{N}_{2}$ on cooling. The sample was out-gassed similarly

(a)

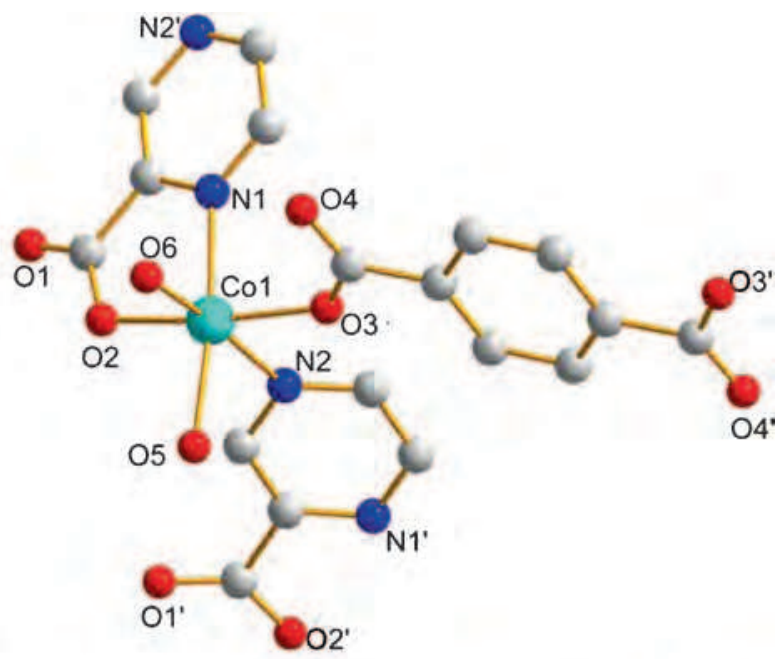

(b)

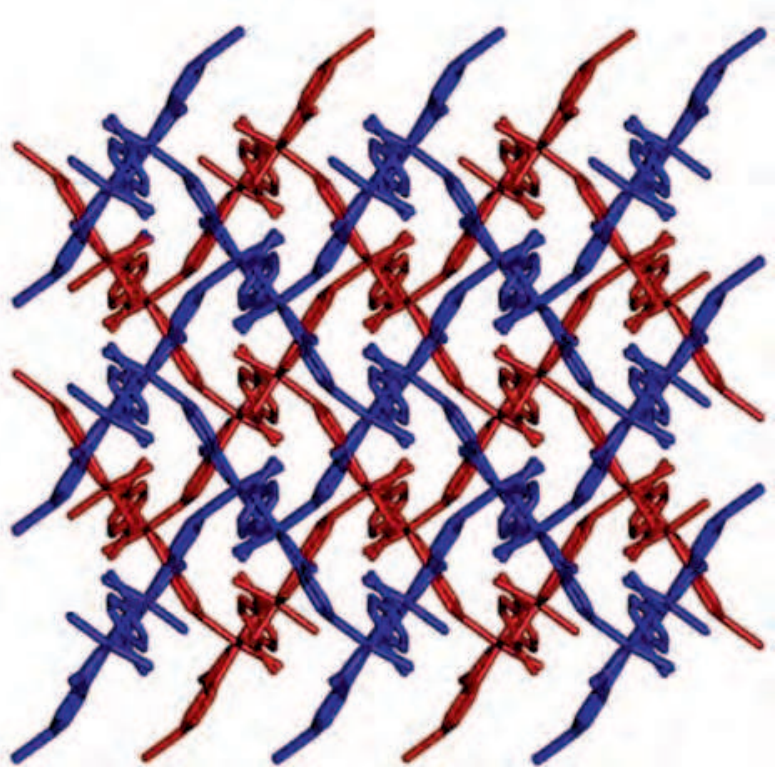

Figure 1. (a) Coordination environment of compound 1; (b) $\mathrm{ABAB}$ arrangement of $2 \mathrm{D}$ sheets of compound $\mathbf{1}$ along 'c' axis. before each measurement for $5 \mathrm{~h}$. All the solvent sorption isotherms were measured at $298 \mathrm{~K}$ while the gas measurements were performed at $195 \mathrm{~K}$.

\section{Results and Discussion}

The solvothermal reaction between pyrazine carboxylic acid (pcaH), 1,4-benzene dicarboxylic acid $\left(\mathrm{bdcH}_{2}\right)$, $\mathrm{NaOH}$, and $\mathrm{Co}\left(\mathrm{NO}_{3}\right)_{2}$ in $\mathrm{H}_{2} \mathrm{O}$ at $160^{\circ} \mathrm{C}$ for 3 days gave wine red coloured crystals of $\left[\mathrm{Co}(\mathrm{pca})(\mathrm{bdc})_{0.5}\left(\mathrm{H}_{2} \mathrm{O}\right)_{2}\right]$ (1). Single crystal X-ray analysis (SC-XRD) of compound $\mathbf{1}$ revealed that the compound crystallizes in

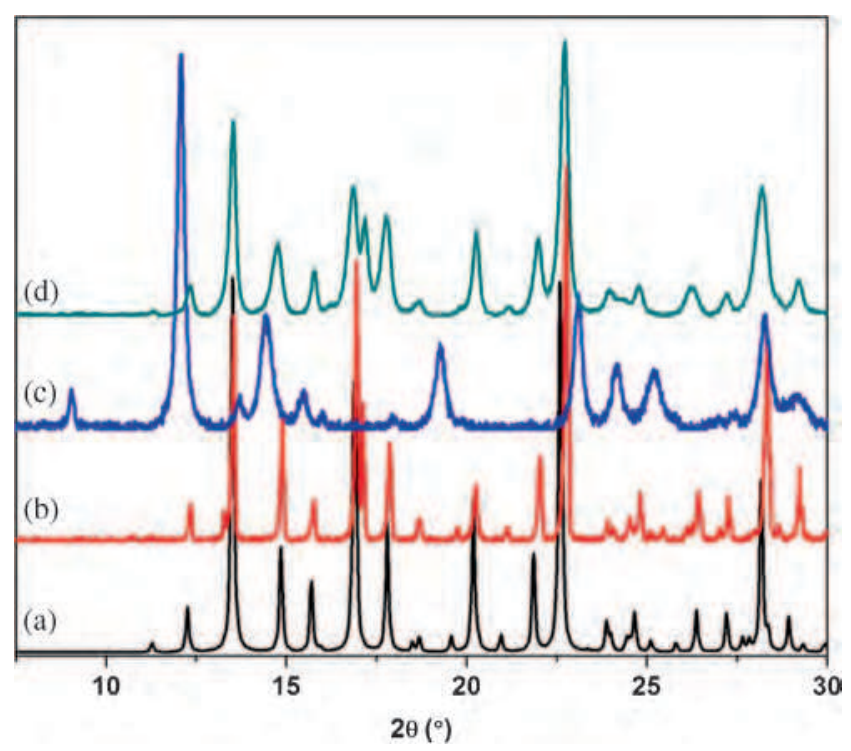

Figure 2. Powder X-ray diffraction patterns of different phases of compound 1. [(a) Simulated, (b) As-synthesized, (c) Dehydrated, (d) Rehydrated].

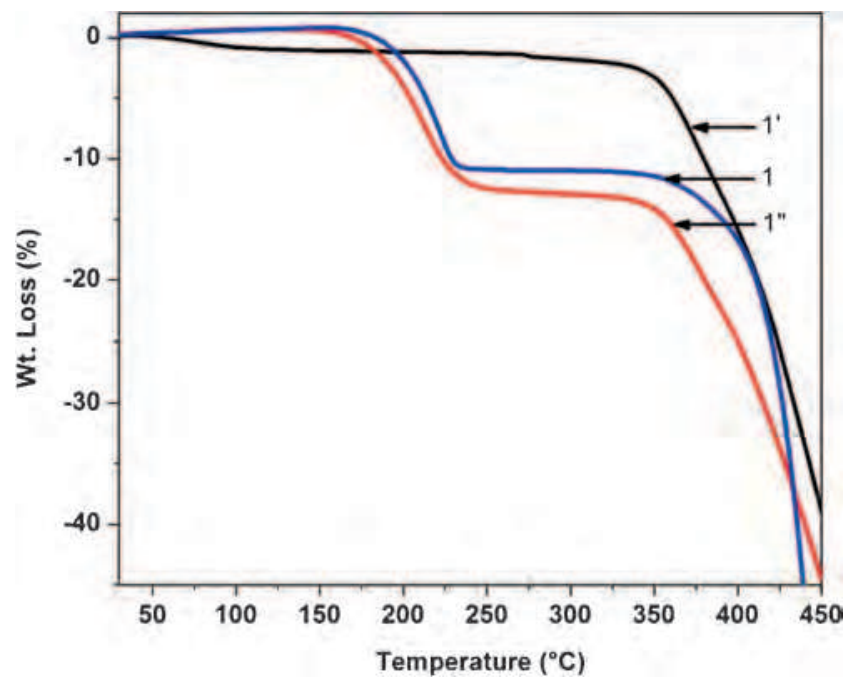

Figure 3. Thermogravimetric analysis of different phases of compound $\mathbf{1}$. (1 as-synthesized, $\mathbf{1}^{\prime}$ dehydrated, $\mathbf{1}^{\prime \prime}$ rehydrated). 
orthorhombic crystal system with space group Pbca. One pca ligand and half bdc ligand are connected to the central $\mathrm{Co}$ (II) metal ion to make the overall framework neutral. Two water molecules coordinate to the metal centre from the opposite sides of pca nitrogen atoms.

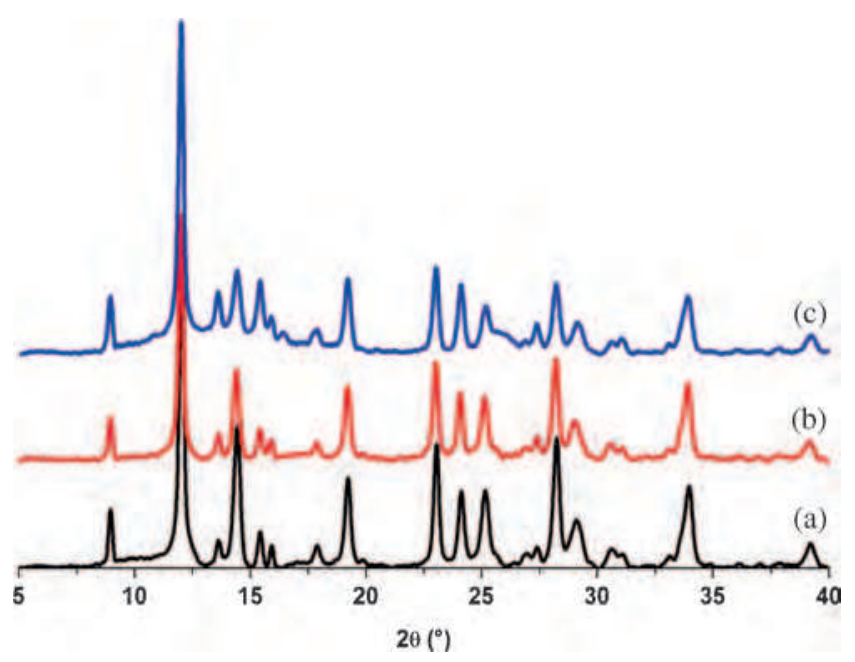

Figure 4. Powder X-ray diffraction (PXRD) patterns of compound $\mathbf{1}^{\prime}$. a) de-solvated phase $\left(\mathbf{1}^{\prime}\right)$, b) $\mathbf{1}^{\prime}$, exposed to THF for 8 days, c) $\mathbf{1}^{\prime}$, exposed to $\mathrm{MeOH}$ for 8 days.

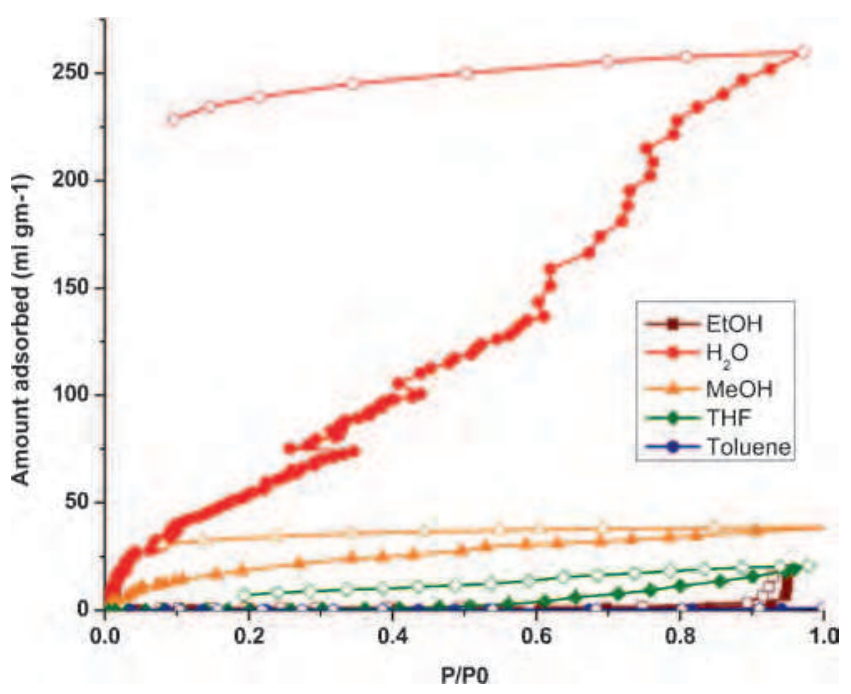

Figure 5. Selective solvent sorption isotherms for $\mathbf{1}^{\prime}$ at 298 K. (Filled symbols indicate adsorption, and open symbols indicate desorption.)
The metal ions adopt octahedral environment with $\mathrm{N}_{2} \mathrm{O}_{4}$ donor set (figure 1a). The adjacent $\mathrm{Co}$ (II) centres are connected by pyrazine nitrogens forming 1D Zigzag chain along $b$ axis. The bdc ligand with mono-dentate coordination mode connect these 1D zigzag chain of $\mathrm{Co}(\mathrm{II})$ pyrazine to give rise to $2 \mathrm{D}$ sheet structure along ' $c$ ' axis. The sheets are arranged one above the other in $\mathrm{ABAB}$ fashion and formed hydrogen bonded pseudo3D interpenetrated structure (figure $1 \mathrm{~b}$ ). The free carboxylate oxygen from both pca and bdc ligands form hydrogen bonds with the water molecules from adjacent A layers present above and below it. Also, the B layer form hydrogen bonds with neighbouring B layer present above and below it. ${ }^{38}$ The phase purity of the bulk sample was confirmed by overlapping Powder $\mathrm{X}$-ray diffraction patterns (PXRD) of as-synthesized material with simulated PXRD pattern from SC-XRD (figure 2).

The thermogravimetric analysis (TGA) of compound 1 in $\mathrm{N}_{2}$ atmosphere revealed that the compound is stable up to $160^{\circ} \mathrm{C}$ (figure 3 ). Above $160^{\circ} \mathrm{C}$, the compound starts losing coordinated water molecules and complete water loss occurred at $\sim 230^{\circ} \mathrm{C}$ forming dehydrated phase $\left[\mathrm{Co}(\mathrm{pca})(\mathrm{bdc})_{0.5}\right]\left(\mathbf{1}^{\prime}\right)$. The dehydrated phase $\mathbf{1}^{\prime}$ is stable up to $360^{\circ} \mathrm{C}$ after which it starts decomposing. The formation of dehydrated phase was also confirmed by TGA and PXRD analysis. To get the dehydrated phase, compound 1 was heated at $140^{\circ} \mathrm{C}$ under vacuum for $12 \mathrm{~h}$. The TGA analysis of dehydrated sample showed negligible weight loss till $160^{\circ} \mathrm{C}$ which confirmed the complete removal of coordinated water molecules. The comparison between PXRD patterns of as-synthesized and dehydrated form showed that on dehydration the original structure transforms to a new structure. But interestingly, upon exposure to the water vapour, the dehydrated phase again transforms back to original hydrated structure (1") as was evident from the PXRD analysis (figure 2). Also, the TGA of this rehydrated form shows weight loss corresponding to two water molecules. We also exposed the dehydrated phase $\mathbf{1}^{\prime \prime}$ to other polar coordinating solvents $\mathrm{MeOH}$ and THF. Surprisingly, we did not observe any structural change in $\mathbf{1}^{\prime \prime}$ upon exposure to $\mathrm{MeOH}$ or THF (figure 4). The

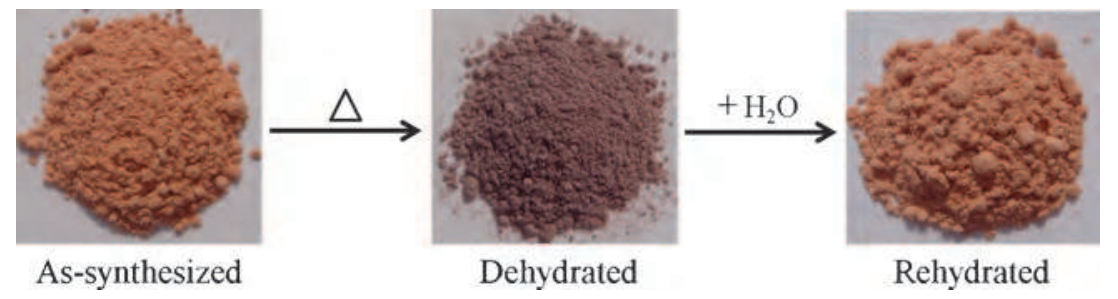

Figure 6. Photograph showing visible colour changes in compound $\mathbf{1}$. 
above results demonstrate that the reversible structural change observed in the compound is highly selective for water.

To further confirm the selective uptake of water, we measured sorption isotherms of different adsorbates $\left(\mathrm{H}_{2} \mathrm{O}, \mathrm{MeOH}, \mathrm{EtOH}, \mathrm{THF}\right.$, Toluene) having varying polarities with compound $\mathbf{1}^{\prime}$ volumetrically. As expected, the compound 1' showed non-porous behaviour towards gas molecules. The sorption profile

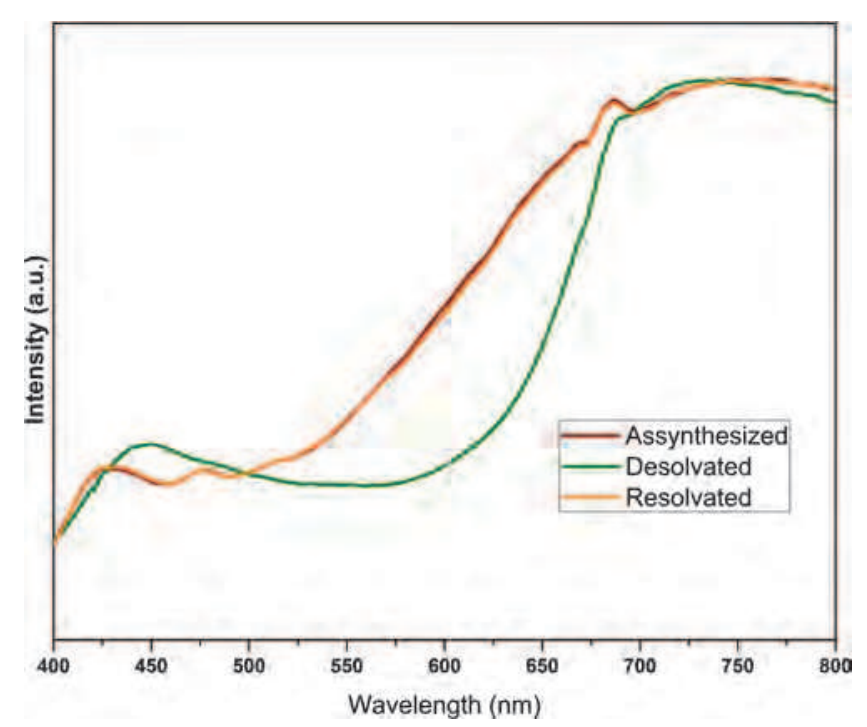

Figure 7. Solid-state UV spectrum of as-synthesized, desolvated and resolvated phases of compound $\mathbf{1}$.

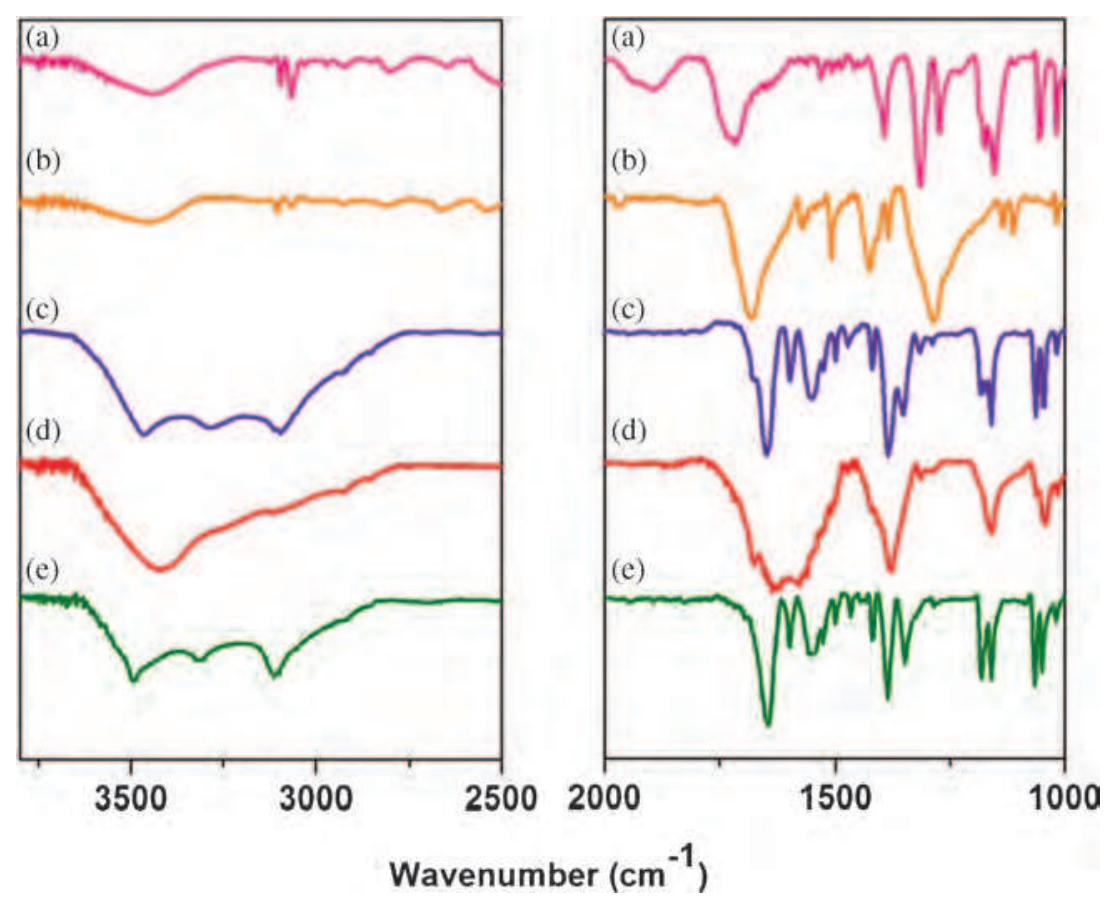

Figure 8. Comparison between the selected area of FT-IR spectra for (a) pca, (b) bdc, (c) as-synthesized, d) desolvated and e) resolvated phases of compound 1. compound 1. maximum again at $425 \mathrm{~nm}\left(\mathbf{1}^{\prime \prime}\right)$.

of water showed linear increase in water uptake with increasing pressure with a maximum uptake of $200 \mathrm{~mL}$ per gram (figure 5). This $\mathrm{H}_{2} \mathrm{O}$ uptake corresponds to uptake of two water molecules per formula unit. Desorption profile showed a large hysteresis with negligible weight loss even at reduced pressure. On the other hand, the sorption profiles of polar coordinating solvents like $\mathrm{MeOH}$, EtOH, THF showed insignificant uptakes. These results are in good agreement with structural rigidity of $\mathbf{1}^{\prime}$ towards $\mathrm{MeOH}$ and THF as mentioned above. The selective water uptake can be assigned to the smaller size and polar nature of water molecule along with the flexible nature of the compound driven by host-guest interaction. The above results confirm the selective water sorption behaviour of

In addition to reversible structural transformation, we observed that the compound shows reversible visible colour change corresponding to hydrated and dehydrated phases (figure 6). This prompted us to measure the solid-state UV-Vis spectra of different phases of compound 1 to ensure the complete structural transformation (figure 7). The as-synthesized pink compound (1) shows absorbance maximum at $425 \mathrm{~nm}$ which on dehydration shifts to $450 \mathrm{~nm}$ with change in colour from pink to dark purple $\left(\mathbf{1}^{\prime}\right)$. On rehydration, the dark purple coloured dehydrated phase again changes to pink coloured rehydrated phase showing absorbance 
To gain insights into the reversible structural transformation on water exposure and associated colour change, we tried to get the structure of desolvated phase $\mathbf{1}^{\prime}$ by SC-XRD analysis. We heated the single crystals of 1 under reduced pressure and collected the SC-XRD data. Unfortunately, after several attempts we could not get the structure of desolvated phase. We recorded IR spectra of both the pure ligands, as-synthesized, desolvated and resolvated compounds to get the hint of possible structural changes around central metal ion (figure 8).

The peak corresponding to the coordinated water molecule $\left(3110 \mathrm{~cm}^{-1}\right)$ is present in both as-synthesized and rehydrated compound but absent in dehydrated phase. ${ }^{38}$ This clearly indicates that on heating, both the water molecules are removed from as-synthesized compound which are regained upon rehydration in $\mathbf{1}^{\prime \prime}$. Also, the peak corresponding to free carboxylates (1648 s and $1596 \mathrm{w} \mathrm{cm}^{-1}$ ) become broad on dehydration which can be recovered on hydration indicating change in the coordination ability of the free carboxylates. ${ }^{38}$ Hence, we propose that on heating, compound $\mathbf{1}$ loses both the coordinate molecules and transforms to dehydrated phase $\mathbf{1}^{\prime}$ creating open metal sites. This change in coordination environment around central metal atom leads to a change in visible colour. On rehydration owing to small size and polar nature of water, the original structure can be recovered.

\section{Conclusion}

We have synthesized 2D metal organic frameworks with formula $\left[\mathrm{Co}(\mathrm{pca})(\mathrm{bdc})_{0.5}\left(\mathrm{H}_{2} \mathrm{O}\right)_{2}\right]$. The compound shows reversible, dynamic structural transformations between two states with visible change in colour. The reversible structural transformation between assynthesized $\left[\mathrm{Co}(\mathrm{pca})(\mathrm{bdc})_{0.5}\left(\mathrm{H}_{2} \mathrm{O}\right)_{2}\right]$ and dehydrated $\left[\mathrm{Co}(\mathrm{pca})(\mathrm{bdc})_{0.5}\right]$ states was confirmed by IR spectroscopy, TGA and PXRD data. The desolvated compound shows selective sorption of water. The selective uptake of $\mathrm{H}_{2} \mathrm{O}$ over other organic solvents like $\mathrm{MeOH}$, $\mathrm{EtOH}, \mathrm{THF}$ and toluene by desolvated phase is ascribed to the strong affinity of polar solvent to the open metal sites and H-bonding interaction between the host and guest. This $2 \mathrm{D}$ framework has the potential to separate water in alcohols and can be used in bio-alcohol purification.

\section{Supplementary Information}

Crystallographic data for the structural analysis have been deposited with the Cambridge Crystallographic data Centre, CCDC 870178 for complex 1. Copies of the data can be obtained free of charge at www. ccdc.cam.ac.uk/conts/retrieving.html [or from the Cambridge Crystallographic Data Centre, 12 Union Road, Cambridge CB2 1EZ, UK, Fax: (internet) +44-1223336-033; E-mail: deposit@ccdc.cam.ac.uk

\section{Acknowledgements}

S.S.N. is thankful to CSIR for research fellowship. We are grateful to IISER Pune for research facilities and DST (Project no. GAP/DST/CHE-12-0083) and DAE (Project no. 2011/20/37C/06/BRNS) for financial support.

\section{References}

1. Yoon M, Suh K, Natarajan S and Kim K 2013 Angew. Chem. Int. Ed. $\mathbf{5 2} 2688$

2. Li S-L and Xu Q 2013 Energy Environ. Sci. 61656

3. Laberty-Robert C, Valle K, Pereira F and Sanchez C 2011 Chem. Soc. Rev. 40961

4. Hill G J, Nelson E, Tilman D, Polasky S and Tiffany D 2006 Proc. Natl. Acad. Sci. U. S. A. 10311206

5. Gnansounou E and Dauriat A 2010 Bioresour. Technol. 1014980

6. Luque R, Herrero-Davila L, Campelo J M, Clark J H, Hidalgo J M, Luna D, Marinas J M and Romero A A 2008 Energy Environ. Sci. 1542

7. Sano T, Yanagishita H, Kiyozumi Y, Mizukami $F$ and Haraya K J 1994 Membr. Sci. 95221

8. Okamoto K, Kita H, Horii K and Tanaka K 2001 Ind. Eng. Chem. Res. 40163

9. Tuan V A, Li S, Falconer J L and Noble R D 2002 J. Membr. Sci. 196111

10. Nagarkar S S, Chaudhari A K and Ghosh S K 2012 Inorg. Chem. 51572

11. Kitagawa S and Matsuda R 2007 Coord. Chem. Rev. 251 2490

12. Yaghi O M, O'Keeffe M, Ockwig N W, Chae H K, Eddaoudi M and Kim J 2003 Nature 423705

13. Horike S, Umeyama D and Kitagawa S 2013 Acc. Chem. Res. 4611

14. Nagarkar S S, Joarder B, Chaudhari A K, Mukherjee S and Ghosh S K 2013 Angew. Chem. Int. Ed. 52 2881

15. Czaja A U, Trukhan N and Mueller U 2009 Chem. Soc. Rev. 381284

16. Stock N and Biswas S 2012 Chem. Rev. 112933

17. Zhao D, Meek S T, Greathouse J A and Allendorf M D 2011 Adv. Mater. 23249

18. Perry J J, Perman J A and Zaworotko M J 2009 Chem. Soc. Rev. $\mathbf{3 8} 1400$

19. Cui Y, Yue Y, Qian G and Chen B 2011 Chem. Rev 112 1126

20. Tanabe K K and Cohen S M 2011 Chem. Soc. Rev. 40 498 
21. Kuppler R J, Timmons D J, Fang Q R, Li J R, Makal T A, Young M D, Yuan D Q, Zhao D, Zhuang W J and Zhou H C 2009 Coord. Chem. Rev. 2533042

22. Ling Y, Chen Z-X, Zhai F-P, Zhou Y-M, Weng L-H and Zhao D-Y 2011 Chem. Commun. 477197

23. Shimomura S, Horike S, Matsuda R and Kitagawa $\mathrm{S}$ 2007 J. Am. Chem. Soc. 12910990

24. Maji T K, Matsuda R and Kitagawa S 2007 Nature Mat. 6142

25. Horike S, Shimomura S and Kitagawa S 2009 Nature Chem. 1695

26. Manna B, Chaudhari A K, Joarder B, Karmakar A and Ghosh S K 2013 Angew. Chem. Int. Ed. 52998

27. Joarder B, Chaudhari A K, Nagarkar S S, Manna B and Ghosh S K 2013 Chem. Eur. J. 1911178

28. Li J-R, Kuppler R J and Zhou H-C 2009 Chem. Soc. Rev. 381477

29. Zhang J and Chen X-M 2008 J. Am. Chem. Soc. 130 6010
30. Yanai N, Umera $\mathrm{T}$, Inoue $\mathrm{M}$, Matsuda R, Fukushima T, Tsujimoto M, Isoda $\mathrm{S}$ and Kitagawa S $2012 \mathrm{~J}$. Am. Chem. Soc. 1344501

31. Gagnon K J, Beavers C M and Clearfield A 2013 J. Am. Chem. Soc. 1351252

32. Coronado E and Espallargas G M 2013 Chem. Soc. Rev. 421525

33. SAINTPlus (Version 7.03) 2004 (Madison, WI: Bruker AXS Inc.

34. Sheldrick G M 1997 SHELXTL, Reference Manual, Version 5.1 (Madison, WI: Bruker AXS)

35. Sheldrick G M 2008 Acta Crystallogr. Sect. A 112

36. Farrugia L J 2009 WINGX version 1.80.05 (Glasgow: University of Glasgow)

37. Spek A L and PLATON A 2005 Multipurpose Crystallographic Tool (Utrecht, The Netherlands: Utrecht University)

38. Nagarkar S S, Das R, Poddar P and Ghosh S K 2012 Inorg. Chem. $\mathbf{5 1} 8317$ 